\title{
Free Coding: A New Reversal Theory Methodology?
}

\author{
Michael J. Apter \\ Apter Research, LLC
}

\author{
Gareth Lewis \\ Independent Researcher
}

\begin{abstract}
This paper introduces, illustrates, and discusses the possibility of a new way of organizing data in reversal theory research. In reversal theory, questionnaire items are often situations taken to represent motivational states, e.g. working on taxes may be supposed a priori to occur in the telic state and used to indicate the presence of this state. An alternative more open approach would be to present situations to the respondent and ask them to indicate which motivational state(s) they might experience in those situations. This would involve what we might call free coding. Instead of inferring dominance profiles (say) from frequency judgements of different states, each state prevalence of a respondent would be judged from the number of different situations seen by that respondent to relate to each motivational state. Among other things this allows us to measure some new kinds of personality variables: we have called these focus, generativity, and flexibility. Situations as well as people can also have distinct characteristics or motivational profiles. This is a discussion paper that introduces this new approach and explores it with a preliminary empirical demonstration in the form of a State Pattern Investigation (SPIN).
\end{abstract}

Keywords: Free coding; motivation; state measure; psychometrics; personality; motivational prevalence; situation

The central idea that is being introduced in this paper is that of what we might call free coding. This is a kind of respondent-centered coding and is distinct from the notion of open coding (as used, for instance in grounded theory), which involves the researcher assigning and labelling concepts and categories based on his or her data in a post hoc way (Glaser, 1992). By contrast, in free coding it is the respondent who indicates which situations are related to which motivational states.

Free coding allows us to judge the importance of a given motivational state in a person's life, not by the frequency with which the respondent judges it to arise (as in current dominance measures), but by the range of different situations in which the respondent reports experiencing this motivational state. We measure this by presenting the respondent with a list of varied situations and asking them to say which values, i.e. motivational states, they associate with each situation (see Figure 1). This pattern of associations of a motivational state over situations then gives us a new kind of indication of how important that motivational state is in the life of the individual concerned. It does so in terms of what we shall call prevalence. We can measure prevalence for each of the eight states for an individual. Thus a given person might, over a large set of items (each item representing a different

Correspondence concerning this article should be addressed to Michael J. Apter. E-mail:mjapter@aol.com situation), cite the telic state five times, the paratelic state three times, the conforming state ten times, and so on, thus showing the relative importance of each in their life. This gives us a new kind of personality profile - a prevalence profile.

It will be realized that this profile is one in which it is the respondent who creates the connections between motivational states and situations and not the researcher. This is why it has been called free coding. Thus, as experimenters we do not have to assume that, say, tennis is paratelic: we can see if respondents associate the paratelic state with it, and indeed other states as well. The whole approach is respondentbased, and in this respect, it makes a radical break with other reversal theory measures (and arguably with most other personality test measures). In this way the resulting profile captures the phenomenological spirit of reversal theory, and perhaps does so better than tests in which the experimenter starts from the assumption that items actually do have the qualities we assign to them a priori.

The starting point of any study using free coding is the creation of a list of a variety of everyday situations. Variety is important so that any or all of the states are given a reasonable opportunity to be citable by every individual, thus allowing a complete profile for each individual respondent. The development of the particular list illustrated here was the subject of much debate between the authors. A key problem was how to select situations that would be likely, over the complete set, to be associated with many different motivational states. 


\section{STATE PATTERN-INDICATOR (SPIN)}

Name (optional):

Sex:

Age (optional):

Instructions: For each of the situations in the column on the left, indicate which of the values in the column on the right you would want to try to satisfy. Use the letters to indicate your choice.

- You may choose as many values as you like for each situation.

- You may endorse the same value as often as you wish across situations.

\begin{tabular}{|l|l|}
\hline Situation & $\begin{array}{l}\text { Values pursued - } \\
\text { your choice }\end{array}$ \\
\hline Swearing & \\
\hline Driving & \\
\hline Exercising & \\
\hline Watching a documentary & \\
\hline A family meal & \\
\hline Cleaning teeth & \\
\hline Listening to music & \\
\hline Checking in for a flight & \\
\hline Praising someone & \\
\hline Paying household bills & \\
\hline Travelling to work & \\
\hline Having an argument & \\
\hline Learning a new skill & \\
\hline Enjoying a romantic meal & \\
\hline Taking a shower & \\
\hline Giving a gift & \\
\hline
\end{tabular}

Figure 1. Sample State Pattern-Indicator

Another area of debate was the question of whether situations would be more interesting if they were "weak" or "strong." A situation would be deemed to be strong if it was likely to be consistently and reliably associated across respondents with a single, specific state, or small number of states. To give an everyday example, and following the logic of the construct, it might be reasonably guessed that the situation "having an argument" would be strongly associated across respondents with the negativistic state. Initially such strong situations might seem desirable within the current psychometric paradigm of the quantitative development and testing of items. Weak situations, on the other hand, are those that have the potential to be associated with multiple motivational states. In psychometric terms, such weak situations-as-

\begin{tabular}{|l|l|c|}
\hline Style & Description of value & Code \\
\hline SERIOUS & $\begin{array}{l}\text { To accomplish something for } \\
\text { the future; to achieve } \\
\text { something important; to do } \\
\text { something with consequences }\end{array}$ & $\mathrm{A}$ \\
\hline PLAYFUL & $\begin{array}{l}\text { To enjoy myself in the moment; } \\
\text { to do something fun; to do } \\
\text { something for its own sake }\end{array}$ & B \\
\hline CONFORMING & $\begin{array}{l}\text { To do what I am supposed to } \\
\text { do; to do what is expected of } \\
\text { me; to do my duty }\end{array}$ & C \\
\hline REBELLIOUS & $\begin{array}{l}\text { To do what I am not supposed } \\
\text { to do; to be defiant; to break } \\
\text { rules }\end{array}$ & D \\
\hline MASTERFUL & $\begin{array}{l}\text { To be powerful; to be in control; } \\
\text { to dominate }\end{array}$ & E \\
\hline SYMPATHETIC & $\begin{array}{l}\text { To develop close relationships } \\
\text { with others; to be a good friend; } \\
\text { to be intimate }\end{array}$ & F \\
\hline SELF-ORIENTED & $\begin{array}{l}\text { To do something primarily for } \\
\text { myself; to put myself first }\end{array}$ & $\mathrm{G}$ \\
\hline OTHER-ORIENTED & $\begin{array}{l}\text { To do something primarily for } \\
\text { others; to help others }\end{array}$ & $\mathrm{H}$ \\
\hline
\end{tabular}

items would be considered unhelpful and unreliable. But in reversal theory terms, however, they contain more information than strong items: They tell us more. The phenomenological nature of reversal theory and evidence from qualitative research (Lewis, 2016) suggest that responses to such motivationally ambiguous (i.e. weak) situations can be extremely rich in research terms. For the research to be described below, a list of 16 situations was chosen, which intuitively represented a mix of weak and strong situations, and which it was felt could between them be associated to some degree or another with all eight motivational states.

Only by administering the instrument would it become clear that all the states included are indeed likely to be cited from time to time. The point here is that every state has 
to have the reasonable possibility of being represented, otherwise the full range making up profiles will effectively be truncated. Using an instrument developed in this way, it was possible to construct any given respondent's motivational profile by observing how frequently, across all the situations, each motivational state was endorsed.

In a sense, this is a technique rather than a test, because it does not have fixed items. Each user of the technique can devise his or her items (or situations of interest). In choosing items for such a test, we can make the following liberating assumptions. Firstly, a single situation can be associated with many different states. For example, watching football might be associated by a given respondent with the telic, conforming, mastery, other-oriented and rebellious states. On the other hand, the respondent might associate cleaning teeth with no more than the telic and conforming states. Another respondent might have zero associations between, say, driving to work and any of the states. Secondly, and conversely, a single motivational state might be associated with many different situations. Thus, the playful state might be associated with playing games, watching television, shopping, listening to music, and so on.

We suggest that any questionnaire using free coding be referred to as a type of State Pattern INvestigator (SPIN) (referred to by us in early unpublished research as SPI). This approach provides a new way of providing personality profiles. But these profiles are not dominance profiles in the traditional reversal theory sense. Rather they are, as we have now seen, prevalence profiles: They are concerned with how widely a motivational state, across situations, is implicated in a person's life, not how frequently it occurs. These two prevalence and dominance - may well be statistically related, but they are qualitatively different.

It is still possible, as in current measures of dominance, to interpret the results by comparing the scores for opposing members of a pair by subtracting one score from the other, as in the Motivational Style Profile (MSP; Apter, Mallows, \& Williams, 1998) and other reversal theory questionnaires that measure dominance. In doing so here we would have a kind of prevalence dominance profile. The dominance here would be about the range of responses rather than their frequency in this case, one would be asking which member of each pair had the greater range, ie. was cited in the larger number of situations.

\section{Measuring Metamotivational Variables}

Let us place the preceding argument in a more general reversal theory context. Three kinds of measures have been developed so far in reversal theory: dominance, state, and event-state measures. The first, and most widely used of these, are what we can call trait-like measures, in the form of measures of motivational dominance. In fact, the very first scale developed in reversal theory, the Telic Dominance
Scale (TDS), was of this kind (Murgatroyd, Rushton, Apter, $\&$ Ray, 1978) and the TDS was the principle scale used in reversal theory research for some years. Over 26 papers were published using this scale (Apter \& Desselles, 2001, page 65 for summary table of results). The most widely used dominance scale in current use is the Motivational Style Profile (MSP; Apter et al, 1998) and its workshop-oriented version the Apter Motivational Style Profile (AMSP). Other dominance scales are reviewed in Apter \& Desselles (2001, Chapter 3). The second kind of measure consists of motivational state measures, such as the Reversal Theory State Measure (RTSM; Desselles, Murphy, \& Theys, 2014). The original such measure was the Telic State Measure (Svebak \& Murgatroyd, 1985). These are focused on identifying states at a particular moment. The third kind of measurement is the measure of event states, meaning the dominance profile not of life in general but of a specific event over the period of that event, such as a particular game of tennis, or during some one-off experiment in which one was acting as a subject. The most widely used example of this kind of measure is the Tension and Effort Stress Inventory (TESI; Svebak, 1993) where it has been used mainly during psychophysiological research to measure states during the overall duration of some procedure or task on a single occasion for a particular subject. These are all discussed and compared in Apter \& Desselles (2001).

This leaves open a fourth kind of possible measure which has yet to be widely addressed psychometrically. It would involve the measurement of what have been called "situational states" (Apter \& Desselles, 2001, p.70-73). This would involve measuring states during some identifiable genre of situation (setting, activity, place, occasion, event) across multiple iterations of that situation. Instead of measuring states during a particular one-off game of tennis, for example, one would look for responses by an individual to games of tennis in general over time in order to obtain a situational profile of the tennis situation for the individual concerned. So we would be dealing with something more specific than a trait, but less specific than a particular one-off event, such as a specific game of tennis. It is perhaps surprising that more attention has not been given to the development of a psychometric of this kind since we are often interested in reversal theory research in such questions as "How does this child experience learning mathematics," or "How does a particular athlete experience a particular form of exercise?" In other words, we are often interested in motivation in relation to repeating iterations of the same situations. We are also sometimes concerned with making comparisons between different settings, or tasks, such as "How does this individual's motivational profile compare in general as between work and home?" "What is the motivational difference between practicing and performing a skill?" 
Table 1

The Dataset $(n=11)$

\begin{tabular}{|c|c|c|c|c|c|c|c|c|c|c|c|}
\hline Predictor & Alex & Chris & Devon & Hayden & Jesse & Loren & Micky & Oakley & Pat & Tracy & Val \\
\hline Swearing & de & ge & ag & $\mathrm{cb}$ & $\mathrm{d}$ & $\mathrm{d}$ & ABde & $\mathrm{d}$ & ed & bed & bd \\
\hline Driving & $\mathrm{CD}$ & c & $\mathrm{a}$ & $\mathrm{c}$ & & bGH & $\mathrm{ah}$ & $\mathrm{c}$ & ABeg & $\mathrm{ABe}$ & \\
\hline Exercising & ag & ABdeg & $\mathrm{g}$ & $\operatorname{gad}$ & $\mathrm{g}$ & acg & bg & $\mathrm{g}$ & $\mathrm{ag}$ & $\mathrm{gABe}$ & $\mathrm{ABg}$ \\
\hline Watching a documentary & $\mathrm{g}$ & bg & bg & bg & $\mathrm{b}$ & $\mathrm{b}$ & bg & $\mathrm{a}$ & ag & bgf & $\mathrm{a}$ \\
\hline A family meal & bf & bcfh & $\mathrm{b}$ & hbf & $\mathrm{b}$ & bfh & bf & $\mathrm{f}$ & bfGH & bfg & $\mathrm{h}$ \\
\hline Cleaning teeth & c & $\mathrm{c}$ & $\mathrm{g}$ & ga & $\mathrm{g}$ & $\mathrm{ca}$ & $\mathrm{ag}$ & $\mathrm{c}$ & $\mathrm{gc}$ & cga & \\
\hline Listening to music & bdg & beg & $\mathrm{g}$ & bg & $\mathrm{g}$ & bg & bdg & $\mathrm{a}$ & bg & $\mathrm{bfg}$ & $\mathrm{gb}$ \\
\hline Checking in for a flight & a & $\mathrm{cg}$ & $\mathrm{g}$ & $\mathrm{ca}$ & $\mathrm{a}$ & ac & ag & $\mathrm{c}$ & GHc & $\mathrm{ac}$ & c \\
\hline Praising someone & $\mathrm{h}$ & ace & & fh & $\mathrm{h}$ & fh & acfh & $\mathrm{f}$ & $\mathrm{h}$ & hfa & hf \\
\hline Paying household bills & $\mathrm{c}$ & $\mathrm{c}$ & $\mathrm{c}$ & $\mathrm{c}$ & c & $\mathrm{ca}$ & $\mathrm{ac}$ & $\mathrm{c}$ & $\mathrm{ca}$ & $\mathrm{ca}$ & $\mathrm{c}$ \\
\hline Travelling to work & $\mathrm{a}$ & c & & $\mathrm{ac}$ & $\mathrm{b}$ & $\mathrm{cb}$ & $\mathrm{abg}$ & $\mathrm{c}$ & $\mathrm{caGH}$ & $\mathrm{ca}$ & ca \\
\hline Having an argument & bde & adfGH & $\mathrm{a}$ & ed & $\mathrm{f}$ & $\mathrm{d}$ & adEFg & $\mathrm{e}$ & e & deg & dgh \\
\hline Learning a new skill & BAg & be & ge & $\mathrm{gBA}$ & $\mathrm{g}$ & ga & $\mathrm{ABg}$ & $\mathrm{a}$ & $\mathrm{g}$ & $\mathrm{ABg}$ & $\mathrm{ABdGH}$ \\
\hline Enjoying a romantic meal & & bf & $\mathrm{g}$ & $\mathrm{fGHb}$ & $\mathrm{f}$ & bf & bGH & $\mathrm{f}$ & GHbf & bfg & bfGH \\
\hline Taking a shower & $\mathrm{bc}$ & c & g & $\mathrm{b}$ & $\mathrm{g}$ & bg & ag & $\mathrm{c}$ & $\mathrm{g}$ & $\mathrm{abc}$ & \\
\hline Giving a gift & bh & bcfh & GfH & $\mathrm{hb}$ & $\mathrm{h}$ & hcb & afh & $\mathrm{h}$ & $\mathrm{ABf}$ & hfb & bfGH \\
\hline
\end{tabular}

Note. The letters refer to states chosen: $\mathrm{a}=\mathrm{telic} ; \mathrm{b}=$ paratelic, and so on in order.

Responses highlighted in capitals indicate oppositions-where both states in a domain are chosen.

There is a sense in which the SPIN type of questionnaire is at heart a situational state measure - it measures something about states over situations such as playing golf, having dinner, etc. But the data can then be analyzed in a way that gives rise to a personality profile, and also a new kind of measurement being referred to for the first time here: the measurement of Situational Profiles. The latter will be looked at later in the paper.

\section{Example of Prevalence Profile: Method}

\section{Participants}

This SPIN approach was tried out on an initial opportunity sample of eleven adults, all middle-aged professionals, of both sexes, living in the UK.

\section{Materials}

The questionnaire itself was a single one-sided sheet with two tables (Figure 1). The first table was a list of sixteen everyday situations in column one and an area for collecting responses in column two. The listed situations were intended to represent the eight states. Every respondent was asked to respond to every situation in the second column. (The response might of course be a zero response.) The second table described the eight metamotivational states.

\section{Procedure}

The instructions were: "For each of the situations in the column on the left, indicate which of the values in the column on the right you would want to try to satisfy. Use the letters to indicate your choice. You may choose as many values as you like for each situation. You may endorse the same value as often as you wish across situations."

The second table described each of the eight motivational states using statements of values and labeling each with a letter to represent that particular state. Thus "A" represented the telic state, "B" the paratelic state, and so on. The respondent was asked to put any letters corresponding to a situation against that situation in the first table.

\section{Results}

The whole dataset of responses is shown in Table 1. The data can be analyzed in various ways. A vertical column represents the data for an individual and shows the relative importance to that individual of the different motivational states. The data for an individual can be represented as a scatter plot or summarized in a simple bar chart. For instance, Figure 2 shows Micky's profile. (The names are not real names.) The degree of prevalence of each state can be read off. Similarly, the degree of salience of a pair can be identified by adding the scores for both members of the pair in question. In Micky's case, the telic/paratelic pair is the most salient.

Although the chart looks somewhat like an MSP profile, the data are derived in a different way, as described earlier. (Note that the data is nominal, so the order of the states on the $\mathrm{X}$-axis is arbitrary.) The SPIN technique however also allowed another profile feature to become apparent. This was the possibility that one state alone might dominate not only its partner in the pair, but also all the other states, so that it became a kind of predominant state, or key state. In the 


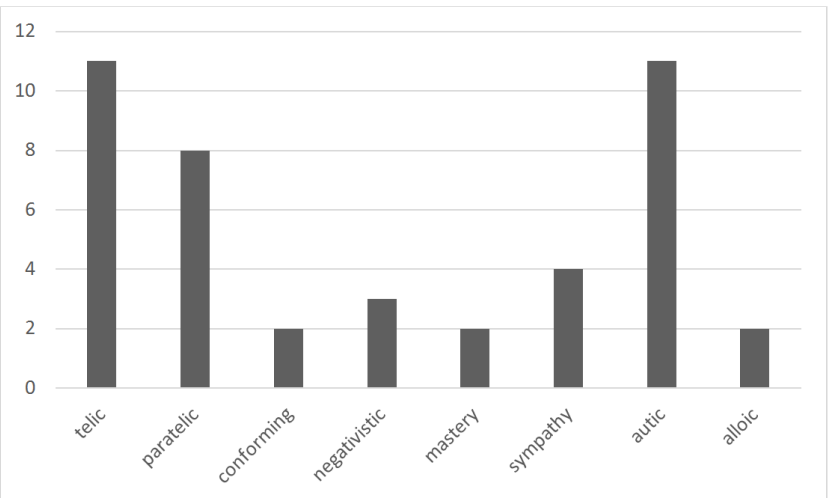

Figure 2. Micky's Profile

case of Micky, the telic and autic states are predominant in this sense. At present, whether a state might count as a key state in a given respondent is a common sense, rather than a quantitative, judgement.

Other inferences may be drawn from this kind of data, and examples will be interspersed in the discussion that follows.

\section{Some Emergent Structural Features of Personality}

As well as providing a recognizable personality profile, free coding technique allows us to measure some emergent structural properties of personality which have not been identified before, and whose possible significance has yet to be explored. At least three such structural properties can be identified, thus opening up a new area of study within reversal theory and perhaps more widely in personality psychology.

\section{Focus.}

Do individuals strongly favor certain states? Do they focus on them? This overlaps the idea of key states, but the point about focus is not what particular key states might or might not consist of, but whether there are key states at all, and how many. In other words, it is systemic rather than particular. It is about the shape of an individual's whole distribution irrespective of which particular states make up that distribution. Some algorithm needs to be found to quantitatively estimate the focality of a state. Is the distribution smooth (no key states) or jagged (pronounced key states)? The point is that the less the focus, the more the likelihood of a diversity of responses - of "motivational richness." So, there is a sense in which focus and diversity are in opposition to each other. Thus, while Micky (Figure 2) has two key states, Devon (Figure 3) shows a single key state, meaning that Micky is motivationally richer than Devon. Part of the value of the SPIN approach would seem to be its use investigating the way that some people live motivationally rich lives in comparison with others.

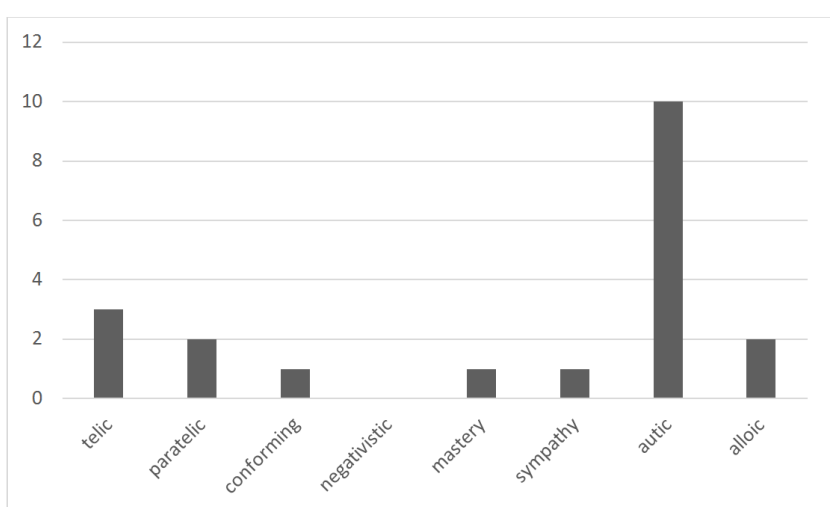

Figure 3. Devon's profile

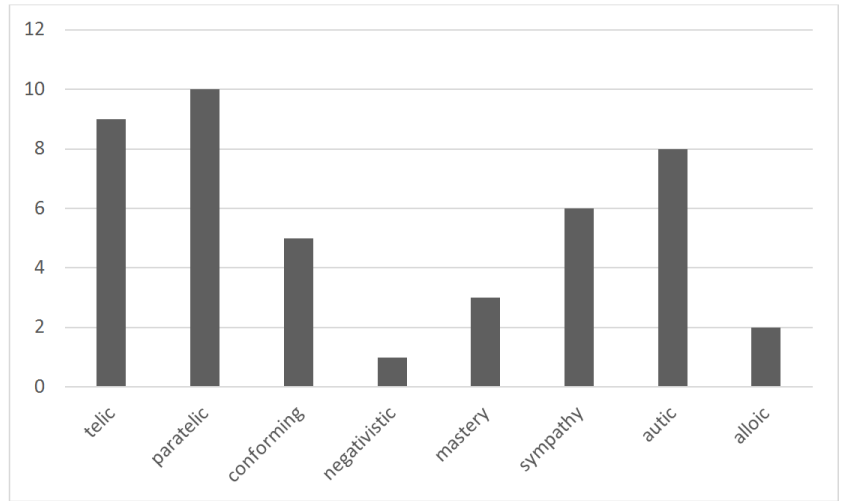

Figure 4. Tracy's profile

\section{Generativity.}

Does the individual make many connections between motivational states and the situations in which they find themselves, or very few? In operational terms, how many responses (total) does the individual make across all the situations? A high generativity score for an individual means that he or she makes connection to multiple ways of experiencing the world.

Tracy (Figure 4) has high generativity, making 44 responses in eight states:

\section{Flexibility.}

How often, across all the situations, does the individual make connections, in relation to a situation, to states that are members of the same pair? How often do we see such "oppositionality" in the profile? Scoring this is a matter of counting the number of occasions on which opposite states are attached to the same situation. It might be possible to think of it as reversibility, taking this to be a personality feature. But this may be misleading because the opposites might occur at different times in different situations, rather than in relation to the same situation, and so we must be careful in our interpretation. But it might give an indication as to re- 
Table 2

Pat's Scatterplot

\begin{tabular}{|c|c|c|c|c|c|c|c|c|}
\hline Predictor & Telic & Paratelic & Conforming & Negativistic & Mastery & Sympathy & Autic & Alloic \\
\hline Swearing & & & & $\mathrm{x}$ & $\mathrm{x}$ & & & \\
\hline Driving & $\mathrm{x}$ & $\mathrm{x}$ & & & $\mathrm{x}$ & & $\mathrm{x}$ & \\
\hline Exercising & $\mathrm{x}$ & & & & & & $\mathrm{x}$ & \\
\hline Watching a documentary & $\mathrm{x}$ & & & & & & $\mathrm{x}$ & \\
\hline A family meal & & $\mathrm{x}$ & & & & $\mathrm{x}$ & $\mathrm{x}$ & $\mathrm{x}$ \\
\hline Cleaning teeth & & & $\mathrm{x}$ & & & & $\mathrm{x}$ & \\
\hline Listening to music & & $\mathrm{x}$ & & & & & $\mathrm{x}$ & \\
\hline Checking in for a flight & & & $\mathrm{x}$ & & & & $\mathrm{x}$ & $\mathrm{x}$ \\
\hline Praising someone & & & & & & & & $\mathrm{x}$ \\
\hline Paying household bills & $\mathrm{x}$ & & $\mathrm{x}$ & & & & & \\
\hline Travelling to work & $\mathrm{x}$ & & $\mathrm{x}$ & & & & $\mathrm{x}$ & $\mathrm{x}$ \\
\hline Having an argument & & & & & $\mathrm{x}$ & & & \\
\hline Learning a new skill & & & & & & & $\mathrm{x}$ & \\
\hline Enjoying a romantic meal & & $\mathrm{x}$ & & & & $\mathrm{x}$ & $\mathrm{x}$ & $\mathrm{x}$ \\
\hline Taking a shower & & & & & & & $\mathrm{x}$ & \\
\hline Giving a gift & $\mathrm{x}$ & $\mathrm{x}$ & & & & $\mathrm{x}$ & & \\
\hline
\end{tabular}

Note. Each x represents a state chosen by the individual.

versibility, or situations where reversals are more likely. In order to illustrate this property, we can see from Pat's scatterplot in Table 2 that there are six oppositions indicated, of which four are autic/alloic. There are 26 such oppositions indicated in the total dataset.

\section{Situational Profiles}

The free coding SPIN technique, then, has a further innovative quality, which is that it is possible to develop profiles not only for personality but also for situations. A horizontal row of the total dataset represents all the data for a particular situation (rather than for a particular respondent).

Just as with personality, patterns of responses differ from situation to situation, and some may be thought of as key situations and will be attached to many different states by a given respondent. But we can also, as for personality, look at structural features of situations, i.e. patterns across whole or partial data sets.

\section{Focus.}

Different situations call more or less widely, simultaneously or serially, on many different motivational states. We say a highly focal situation is one in which there is high agreement as to which motivation is associated with it. For instance, in "paying taxes" (Figure 5) every respondent chose conforming as one of the states, and only one other state (the telic state) was connected with it. To give another example: "Giving a gift" is highly alloic as ten respondents made this association.

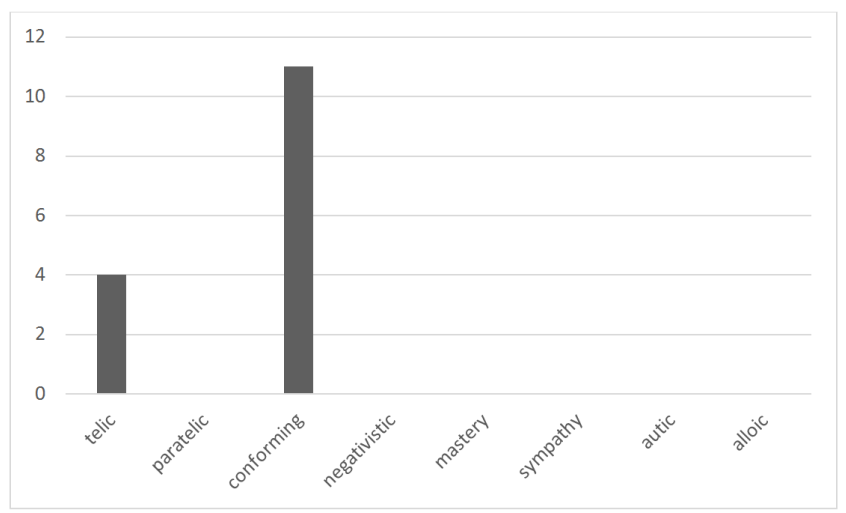

Figure 5. Paying Taxes

\section{Generativity.}

Some situations are attached overall to more states than others, and in this sense have a larger number of motivational connections. In the example below, "having an argument" has 26 responses overall related to seven motivational states (Figure 6). We can therefore claim that this situation is highly generative and is thus motivationally rich. Such situations are particularly interesting from the point of view of research, as, by definition, these situations can be experienced in a range of motivational states. In applied research, these rich situations may help us to understand, for instance, what tools or pedagogical approaches may be brought to bear to make for example learning mathematics, motivationally rich. There is evidence that "helping others" is a motivationally rich context that enhances engagement and satisfaction in a mathematics classroom (Lewis, 2016). It has so many states to 


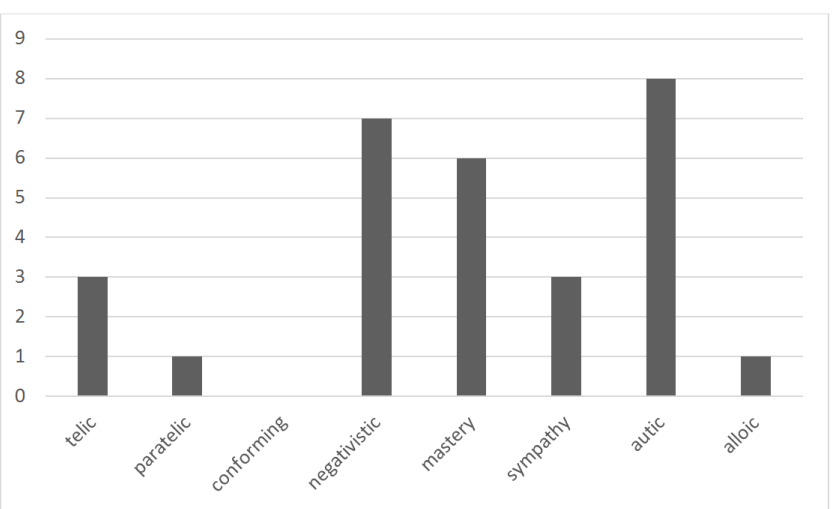

Figure 6. Having an Argument

draw on. Similar considerations are also likely to apply in relation to participation in sport and exercise, among other situations. It should also be emphasized here that this notion of generativity or motivational richness would be inaccessible by traditional psychometric methods and analyses.

Finally, in relation to both individual and situational levels of analysis, focus and generativity are separate and independent, i.e. it is possible for a situation to be both focused and for the one or two focal states to be highly generative.

\section{Flexibility.}

This is how easily the situation calls forth oppositions i.e. opposite states. Since these opposite states refer to the same situation, there is a good chance that a least some of them involve occasions of reversing from one to another during the same situation. For example, "learning a new skill" is associated with five such "reversals," whilst five situations are associated with none. Rather like generativity, situations which more easily elicit such oppositions are likely to be more motivationally rich than those that do not.

\section{Conclusions}

We have here developed a new kind of psychometric approach, the SPIN approach based on the technique of free coding. As described here, a SPIN has the following features:

- It provides a way for iterated events, as experienced by a respondent, - e.g. taking examinations, sunbathing, paying bills - to be measured in motivational terms. This data can be aggregated across respondents.

- It allows for situations as well as personality to be measured in motivational terms - in this way situations come to be discerned as having distinct motivational characteristics of their own that can be represented as situational profiles.

- It allows prevalence of motivational states to be measured as well as dominance, i.e. it measures "popularity" of states as experienced by individuals over events. These patterns of popularity can then be aggregated for groups.

- It introduces structural features of personality that are new to reversal theory and have not been measured before, i.e., focus, generativity and flexibility.

- It is phenomenological and respondent-dependent, meaning that it does not depend on a priori item validity.

- SPIN style questionnaires can be constructed for each particular purpose, so there is no single SPIN, but rather a SPIN format. Of course some particular SPINs may become used widely enough that they become normative standards for comparison in different areas.

This paper sets out the development of this approach and its implementation with a small initial population. In that sense, this is no more than a first step. However, since this approach is in some respects radically different from classical psychometric approaches, there needs to be a program of further research in order to pursue the possibilities opened up by this approach. Some considerations for such further research include:

- A larger trial with many more respondents. This will give broader insight into the performance of SPINs and allow us to start developing norms for different areas.

- With a larger dataset, novel analytic techniques can be applied, and quantitative measures and operational definitions for constructs such as focus and generativity can be developed.

- It is possible to define field-specific subsets of situations for motivational research, such as mathematics education, sports and exercise, sexual behavior, and so on.

- It would be instructive to examine the concurrent relationship of individual SPIN profiles and MSP profiles.

- A SPIN could be used as a "bridge" between quantitative and qualitative research. For instance, the SPIN structure could provide the starting point for interviews to obtain richer data.

- It would be interesting to apply the technique to the study of peak experiences and other kinds of critical experience, both good and bad, and see if these experiences relate to focus, generativity and flexibility. Likewise we could study these structural features in relation to happiness and wellbeing on the one hand and stress and depression on the other.

- It would be interesting to extend the SPI technique to the study of emotions, observing which emotions are most prevalent in an individual's life, and which situations they are associated with.

It can be seen that taking the initial "free coding" step and allowing respondents to determine which items relate to which motivational states, opens up many new possibilities for reversal theory research and adds some new techniques for personality research in general. 


\section{References}

Apter, M. J., \& Desselles, M. (2001). Reversal theory measures. In Apter, M. J. (ed.) Motivational styles in everyday life: A guide to reversal theory. (pp. 55-76) Washington, D.C.: American Psychologial Association.

Apter, M. J., Mallows, R., \& Williams, S. (1998). The development of the Motivational Style Profile. Personality and Individual Differences, 24(1), 7-18.

Desselles, M., Murphy, S. L., \& Theys, E. (2014). The development of the reversal theory state measure. Journal of Motivation, Emotion and Personality, 2(1), 10-21.

Glaser, B. (1992). Basics of grounded theory analysis. Mill Valley, CA: Sociology Press.
Lewis, G. (2016). Disaffection with school mathematics. Netherlands: Sense Publishers.

Murgatroyd, S., Rushton, C., Apter, M. J., \& Ray, C. (1978). The development of the Telic Dominance Scale. Journal of Personality Assessment, 42, 519-528.

Svebak, S. (1993). The development of the Tension and Effort Stress Inventory (TESI). In, Kerr, J.H., Murgatroyd, S. \& Apter, M.J. (Eds.) Advances in reversal theory (pp. 189-204). Amsterdam: Swets \& Zeitlinger.

Svebak, S., \& Murgatroyd, D. (1985). Metamotivational dominance: A multimethod validation of reversal theory constructs. Journal of Personality and Social Psychology, 48, 107-116. 